\title{
Effect of sand particles on flow structure of free jet from a nozzle
}

\author{
M. J. Al-Dulaimi ${ }^{1}$, F. A. Hamad' ${ }^{2}$ A. A. Abdul Rasool ${ }^{3}$ and K. A. Ameen ${ }^{1}$ \\ ${ }^{1}$ Air Conditioning. Eng. Dept, Al- Esraa University College, Baghdad, Iraq. \\ Email: mustafa@esraa.edu.iq \\ ${ }^{2}$ School of Science \& Engineering, Teesside University International Islamic \\ Middlesbrough, UK \\ ${ }^{3}$ Mech. Eng. Dept, college of Engineering, Al-Mustansiriya University, Baghdad, Iraq.
}

\begin{abstract}
The flow structure of a single- and two-phase jet from a $10 \mathrm{~mm}$ nozzle was investigated experimentally and numerically. The measurements were conducted for Reynolds number range of 10007-31561. The velocity was measured at different radial and axial locations from the exit of the nozzle. The distances of the axial locations are $0,2,4,6,8 \mathrm{~cm}$. The twophase flow was created by introducing sand particles as a solid phase. The influence of particles size and mass loading ratio are investigated for particles diameter 220,350,550 $\mu \mathrm{m}$ and loading ratio in range $0.18-1.38$. The results revealed that the introducing solid particles into the jet leads values of velocity due to the transfer of momentum to the particles. It has been observed that the velocity decrease with the higher loading ratio and smaller particles size. The numerical simulation was performed for single- and two-phase jet flow. The flow of air was simulated by implementation RNG K- $\varepsilon$ turbulence model and the discrete phase model to simulate the sand particles. The results form numerical simulation showed a good agreement with experimental results.
\end{abstract}

Keywords: Flow structure; jet flow; air-sand; two phase flow; CFD modelling

\section{INTRODUCTION}

A two-phase jet flow represents a stream of gas carrying solid particles or liquid droplets are encountered in many engineering fields. The influence of particles or droplets on the gas flow in two-phase jet is significant in thermofluid applications like gas cleaning, spraydrying, etc. There are a number of papers published in this area that reflect the need of better understanding of the flow behaviour that affect the process such combustion, drying, cooling of hot objects, etc. The multiphase flow jet has been studied experimentally by a number of researchers as summarised in the following paragraphs.

Fleckhaus et al [1] conducted experiments to investigate the influence of introducing solid particles on the flow structure of air jet. Glass beads with diameter of $64 \mu \mathrm{m}$ and $132 \mu \mathrm{m}$ were used with constant mass loading ratio $(\Gamma)$ of 0.3 to study the jet from a tube of $13 \mathrm{~mm}$ inner diameter and $1 \mathrm{~m}$ length for Reynolds number $=20000$. It was observed that the air velocity profiles of two-phase are steeper than those of the single-phase and the velocity profiles become even steeper with smaller particles. It was also observed that the introducing 
the particles to the jet results in the turbulence dampening and it increases with smaller particles due to increased number of the particles which effect on a larger number of eddies of the air.

Kyong-Yup Paik et al [2] studied experimentally the effect of particle loading ratio and exit velocity on air-particles jet from an orifice of $3 \mathrm{~mm}$ diameter, and $20 \mathrm{~mm}$ length. $\mathrm{Al}_{2} \mathrm{O}_{3}$ particles, of $35-50 \mu \mathrm{m}$ diameter, were used as solid phase and air as carrier gas. They concluded that the particles are accelerated by receiving momentum from the air causing a rapid decrease in air velocity.

Tsuji [3] measured particle laden jet with the use of three devices: A Pitot tube, optical fibre probe ad LDV. The Particle size ranged from 170 to $1400 \mu \mathrm{m}$ wes used as solid phase and air used as the gas phase. The introduction of particles delays the decrease of the centreline velocity and reduction of the jet width were observed for jets laden with fine particles. The particles have the effect of reducing the maximum value of turbulence intensity appeared at $y / D=6$ for single phase flow and moving it further from the nozzle exit.

Milan et al [4] carried out a numerical study to analyse the air solid flow inside a tube and the jet flow at the outlet of the tube. They examined the impact of addition solid particles on velocity profiles. The discrete phase is sand particles of two sizes $(0.25-0.30$ and $0.8-1.0$ $\mathrm{mm}$ ) and of loading ratio (0.72-4.08). The air represents the continuous phase. They found that large particles $(0.8-1.0 \mathrm{~mm})$ had caused a depression in gas velocity at the axis of the jet, as well as at the central zone of the jet, also leading to a faster spreading of the air-solid jet as compared to that of air jet. Larger particles consume more gas flow energy to accelerate because they have bigger mass and inertia. This leads to a reduction in the gas phase kinetic energy which reduces the gas velocity.

Zoltani and Bicen [5] investigated experimentally the behaviour of a confined turbulent two phase jet. A jet of diameter $25.4 \mathrm{~mm}$ and exit velocity of $20 \mathrm{~m} / \mathrm{s}$. The solid phase is represented by $80 \mu \mathrm{m}$ beads with loading ratio of $1.5 \%$. They measured mean velocity profiles at different locations, as well as the fluctuation values for both phases. They noticed that the velocity of particles is less than that of fluid by $8 \%$ near the exit, but led it by $7 \%$ at distance equal of 9 times of jet diameter after the nozzle exit. The velocity profiles of the particles were found to be flatter than those of fluid.

Nan et al [6] carried out a $3 d$ numerical simulation of gas-solid jet to study the dispersion $\mathrm{f}$ particles and its effect to turbulence. Lagrangian frame is used to simulate the particles motion. It was found that the effect of particles on the stream velocity varies with axial location. The particles slow down the stream velocity in the jet centre due to the transfer of momentum from fluid to particles. Also, it was found that fluid fluctuation velocity values are attenuated by the particles.

Pandaba patro et al [7] performed a numerical simulation to study the flow of a confined gas-solid jet. They have studied the effect of solid loading ratio and the solid particles size. In range 50-200 $\mu \mathrm{m}$ and 1-5 respectively. It has been found that the flow field is strongly affected by the presence of solid particles. The velocity and turbulence level were found to be attenuated by solid particles.

In this paper, new experimental data are presented for air jet flow mixed with inhomogeneous sizes of natural sand particles. The inhomogeneous particles sizes with different shapes has direct effect on drag force of each particle which influence the velocity of individual solid particles and the radial air velocity distribution. Experimental and CFD simulation are carried to provide data on radial air velocity distribution for jet velocity $=15$. 
32 and $47 \mathrm{~m} / \mathrm{s}$. The effect of axial distance from the nozzle outlet, particles diameters and loading ratio on radial air velocity distribution are also investigated.

\section{EXPERIMENTAL SETUP}

The experimental facility for jet flow is shown in Figure 1. A centrifugal blower (1) is used to supply air through a PVC pipe (2) to the air-sand mixer. A ball valve (3) was used to control the amount of air entering to the mixer. The sand is supplied to the mixer (4) via the pipe (5) of diameter $12 \mathrm{~mm}$ diameter from the container (6) through a control valve (7). The control valve is a special type used to control the amount of sand entering to the mixer. After mixing the air with the sand, this mixture passes through the injection tube (8). The ratio of the length to diameter for the injection tube is $(L / D=100)$ to ensure adequate length for the flow to be fully developed. The mixture passes through the convergent nozzle (9) of $10 \mathrm{~mm}$ exit diameter before exits to form the jet. The range of tested velocity is $20-50 \mathrm{~m} / \mathrm{s}$. The velocity was measured by a Pitot tube (10) of diameter $0.2 \mathrm{~mm}$ connected to a manometer (11). The manometer is a variable inclination. The inclination so it can detect very small changes. Figure 2 shows the calibration of the pitot tube with a hot wire anemometer. The small diameter of pitot tube prevents the particles from entering inside it. The pitot tube is fixed on a traversing mechanism (12) in order to mover in vertical and horizontal direction to measure the dynamic pressure across the jet at different positions.

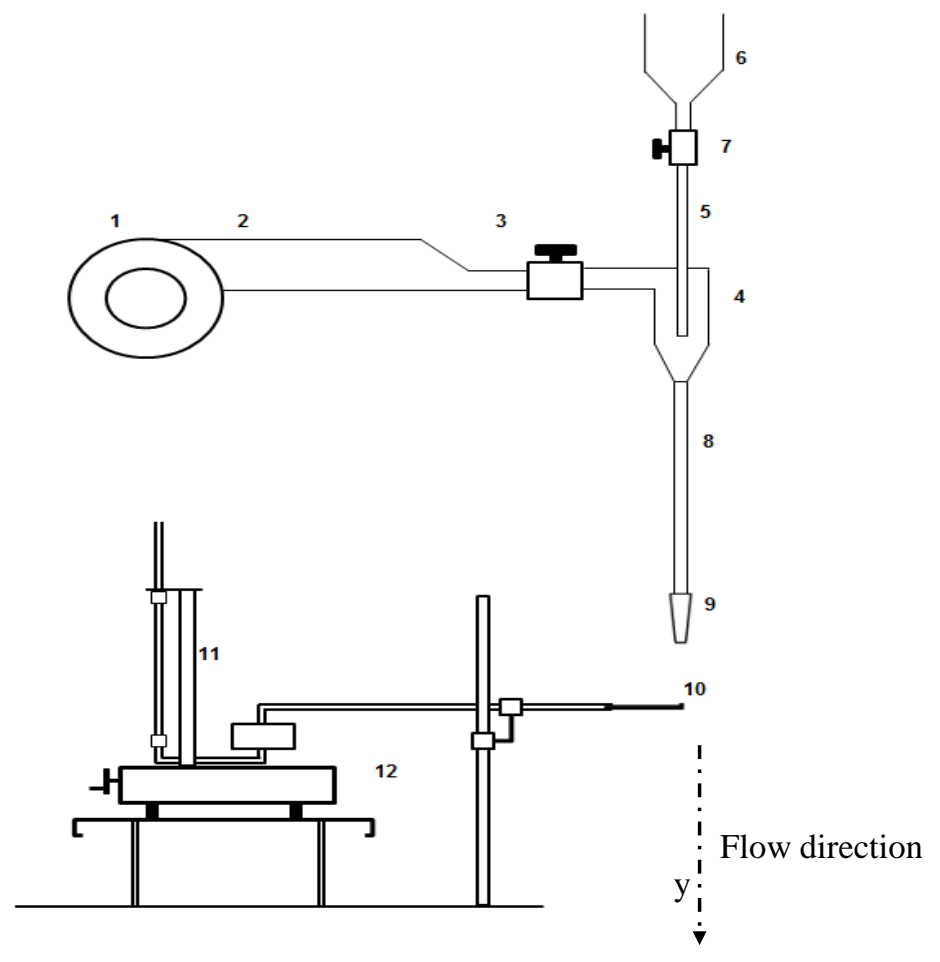

Figure 1. Experimental setup 


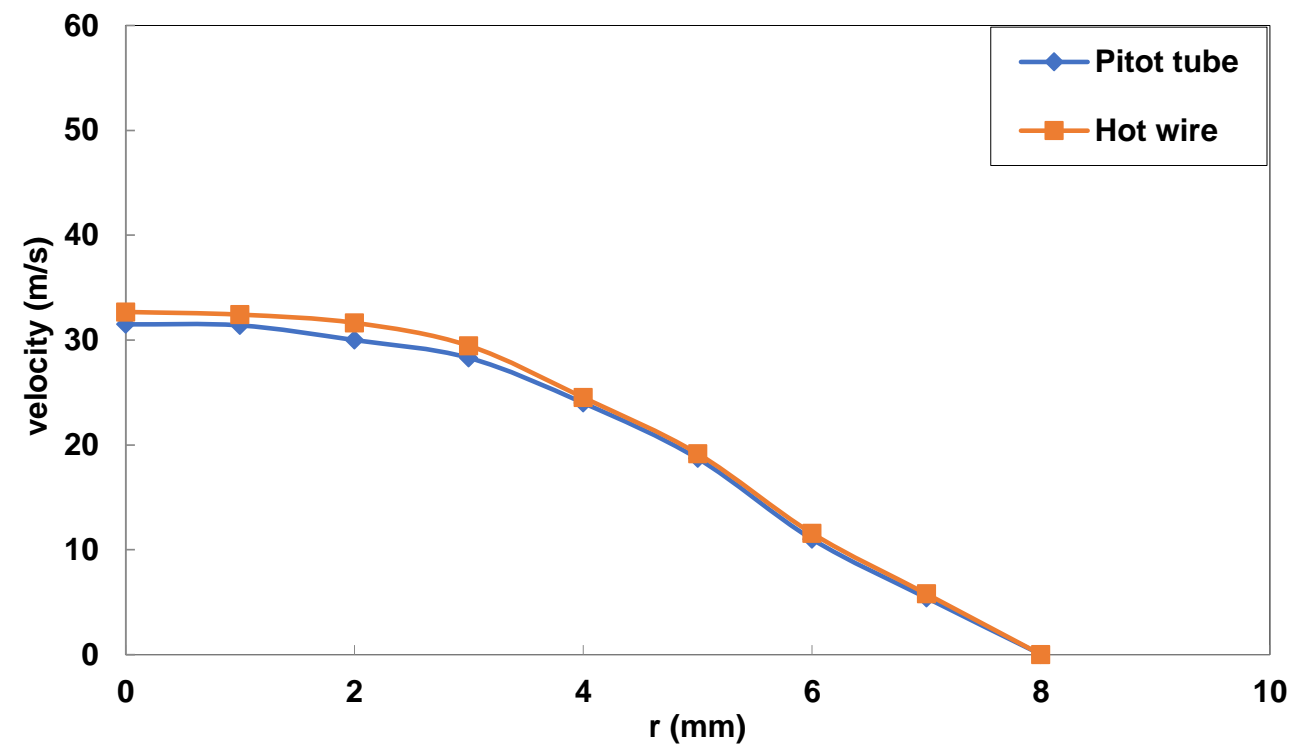

Figure 2. Calibration of Pitot tube

The particles used in the experiments are natural sand, which were sieved to have different size ranges. Five sieves of size $600 \mu \mathrm{m}, 500 \mu \mathrm{m}, 400 \mu \mathrm{m}, 300 \mu \mathrm{m}$ and $200 \mu \mathrm{m}$ were used to separate different sizes of the sand. Three groups of different sizes were obtained from the sieving as shown in Figure 3. These groups were inspected under the microscope to determine the average size of each group, as shown in Figure 4. The average sizes of particles dimeter $\left(d_{p}\right)$ were found to be $220 \mu \mathrm{m}, 350 \mu \mathrm{m}, 550 \mu \mathrm{m}$. The particles density was determined by taking different samples of the sand and dividing their mass by their volume. The density was determined to be $1700 \mathrm{~kg} / \mathrm{m} 3$. The particles do not exactly obey the drag law for sphere due to the irregular shapes of the particles.
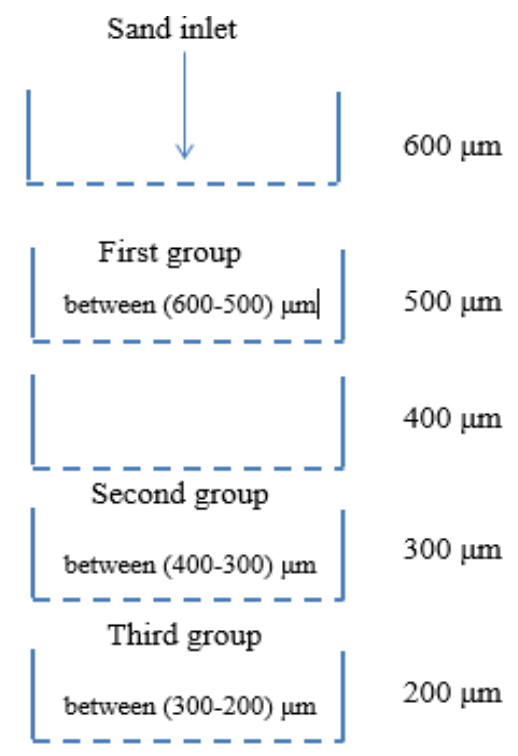

Figure 3. The sieving process 


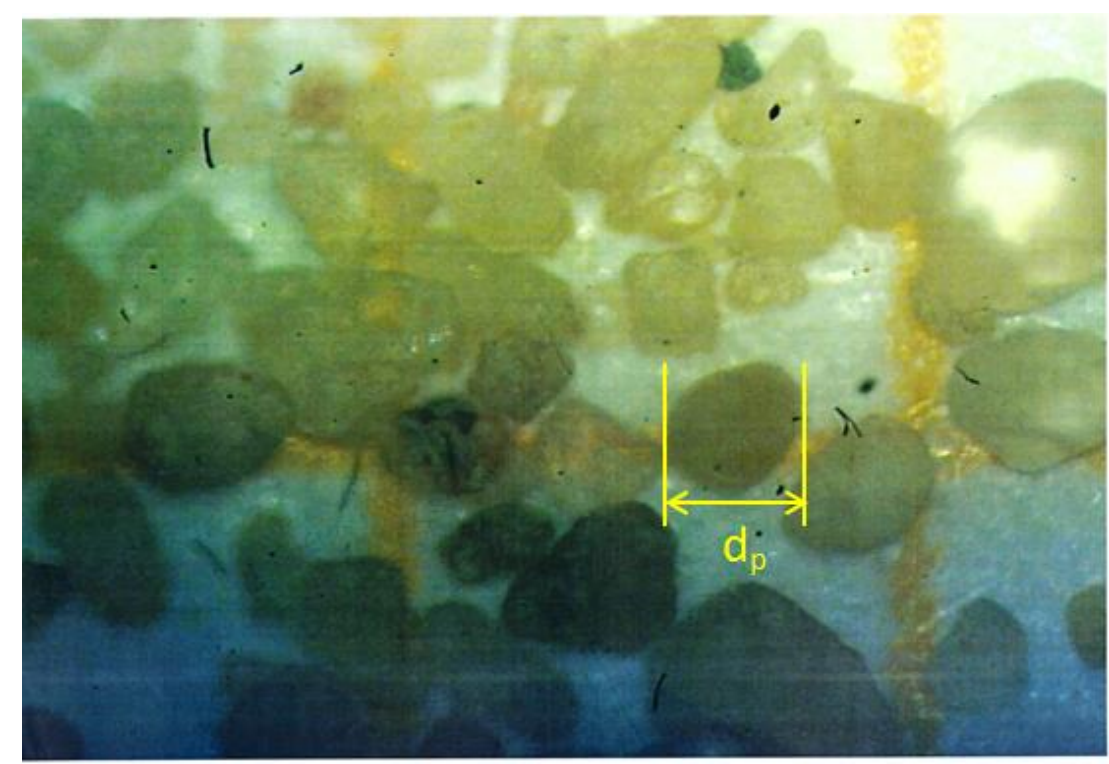

Figure 4. Sand particles under microscope

\section{Experimental Variables}

The flow structures of free air jet at different axial distance to diameter (y/D) ratios were investigated experimentally and numerically under different values of velocity. The effect of loading ratio and particle size on the fluid structure was investigated. The range of nozzle velocities used in the experiments was 15-47 m/s (Re: 10007-31561). Natural sand particles were used as a solid phase with sizes of range $220-550 \mu \mathrm{m}$ and loading ratio of range 0.18 1.38. Experimental variables are listed in Table 1.

Table 1. Experimental Variables

\begin{tabular}{cc}
\hline Variable & Values \\
\hline Air Velocity $\left(U_{J}\right)$ & $15-32-47 \mathrm{~m} / \mathrm{s}$ \\
Loading Ratio $(\Gamma)$ & $0.18-0.21-0.29-0.48-0.51-0.74-0.91-1.38$ \\
Particle Diameter $\left(d_{p}\right)$ & $220-350-550 \mu \mathrm{m}$ \\
Axial distance to diameter ratio & $0-2-4-6-8$ \\
\hline (y/D) & \\
\hline
\end{tabular}




\section{CFD MODEL AND SIMULATION}

\section{Computational Domain and Boundary Conditions}

Figure 5 represents the 3 -dimensional computational domain created for the jet flow vertically from the nozzle into unconfined space. The boundary conditions of the computational domain are shown in Figure 6. The dimensions of the domain are: height 10 $\mathrm{cm}$, width $30 \mathrm{~cm}$ and depth $15 \mathrm{~cm}$. The height is to provide sufficient axial distance to investigate the effect of axial distance to diameter ratio (y/D). The width and the depth are related to another work [8] with same experimental rig.

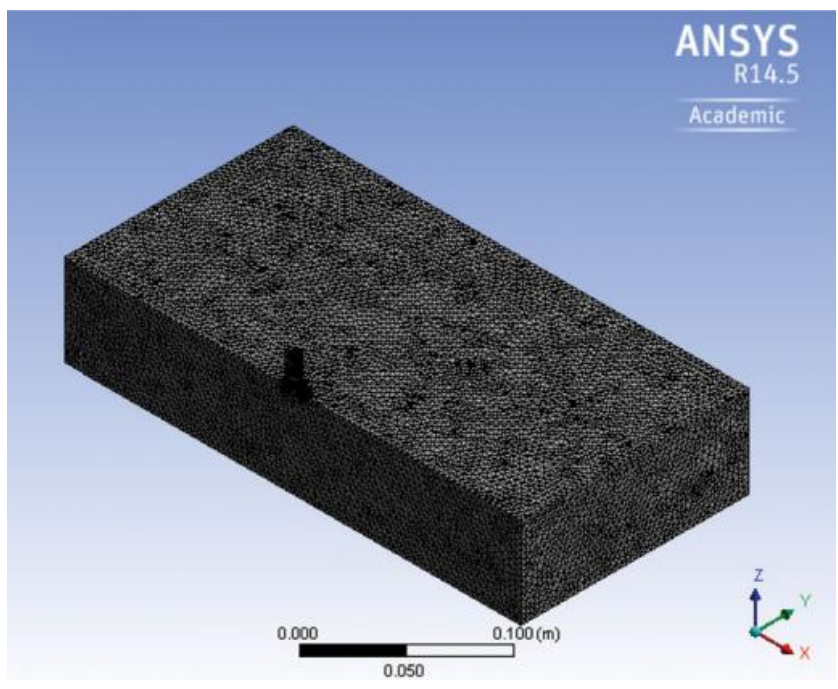

Figure 5. The computational domain

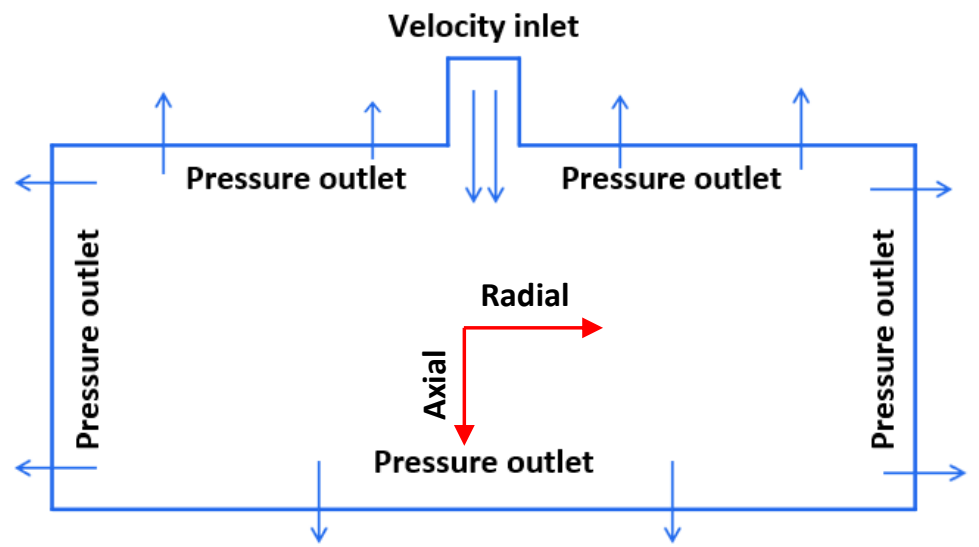

Figure 6 . The boundary conditions 


\section{Governing Equations}

\section{Gas phase}

To simulate the jet flow, equations of mass conservation and momentum conservation with an appropriate turbulence model should to be solved. In this investigation, the flow is 3dimensional, steady, turbulent, and incompressible [9].

Mass conservation equation:

$$
\frac{\partial\left(\rho u_{i}\right)}{\partial x_{i}}=S_{m}
$$

Momentum conservation equation:

$$
\frac{\partial\left(\rho u_{i} u_{j}\right)}{\partial x_{j}}=-\frac{\partial p}{\partial x_{i}}+\frac{\partial}{\partial x_{j}}\left[\mu\left(\frac{\partial u_{i}}{\partial x_{j}}+\frac{\partial u_{j}}{\partial x_{i}}\right)\right]+\frac{\partial\left(-\rho \overline{u_{i}^{\prime} u_{j}^{\prime}}\right)}{\partial x_{j}}++\rho g+F
$$

Boussinesq approximation was used to model Reynolds stresses in Equation (2) [8]:

$$
\frac{\partial\left(-\rho \overline{u_{i}^{\prime} u_{j}^{\prime}}\right)}{\partial x_{j}}=\mu_{t}\left(\frac{\partial u_{i}}{\partial x_{j}}+\frac{\partial u_{j}}{\partial x_{i}}\right)-\frac{2}{3} \rho k \delta_{i j}
$$

where $\mathrm{i}$ or $j=1$ represents the $\mathrm{x}$-direction, $i$ or $j=2$ the y-direction and $i$ or $j=3$ the zdirection and $\boldsymbol{\delta}_{\boldsymbol{i} j}$ is kronecker delta $\left(\boldsymbol{\delta}_{\boldsymbol{i j}}=1\right.$ if $\left.i=j\right)$.

The solution of mass and momentum equations requires that Reynolds stresses and interfacial forces be modelled. The interfacial forces models are important for the evaluation of the pressure and viscous stresses at the interface. These interfacial forces are mass, drag and lift forces. The turbulence model is used to evaluate the turbulent stresses in the momentum equation. The conservation equations are solved incorporating with the interface forces models.

The turbulent viscosity appears in Equation 3 is calculated from:

$$
\mu_{t}=\frac{\rho C_{\mu} k^{2}}{\varepsilon}
$$

RNG K- $\varepsilon$ turbulence model is applied for this investigation. Pulat et al [10] and Heck et al [11] reported that this model reflects the basic features of the jet flow. The conservation equations for the turbulent kinetic energy $k$ and the dissipation rate $\varepsilon$ are:

Kinetic energy, $k$

$$
\rho \frac{\partial}{\partial x_{i}}\left(k u_{i}\right)=\frac{\partial}{\partial x_{j}}\left(\alpha_{k} \mu_{e f f} \frac{\partial k}{\partial x_{j}}\right)+G_{k}-\rho \varepsilon
$$

Dissipation rate, $\varepsilon$

Where

$$
\rho \frac{\partial}{\partial x_{i}}\left(\varepsilon u_{i}\right)=\frac{\partial}{\partial x_{j}}\left(\alpha_{\varepsilon} \mu_{e f f} \frac{\partial \varepsilon}{\partial x_{j}}\right)+C_{1 \varepsilon} \frac{\varepsilon}{k} G_{k}-C_{2 \varepsilon} \rho \frac{\varepsilon^{2}}{k}-R_{\varepsilon}
$$

$G_{k}=\mu_{t} S^{2}, \quad S=\sqrt{2 S_{i j} S_{i j}}, \quad S_{i j}=\frac{1}{2}\left(\frac{\partial u_{j}}{\partial x_{i}}+\frac{\partial u_{i}}{\partial x_{j}}\right), \quad R_{\varepsilon}=\frac{C_{\mu} \rho \eta^{3}\left(1-\eta / \eta_{o}\right)}{1+\beta+\eta^{3}} \frac{\varepsilon^{2}}{k}, \quad \eta=\frac{S_{k}}{\varepsilon}$

Where $G_{k}$ represents the turbulence kinetic energy due to the mean velocity gradients. The constants of this model are recommended by Pulat et al [10]: $\mathrm{C} \mu=0.09, \mathrm{C} \varepsilon_{1}=1.42, \mathrm{C} \varepsilon_{2}=$ 1.68, $\alpha_{k}=\alpha_{\varepsilon} 1.393, \eta_{o}=4.38$ and $\beta=0.012$ 


\section{Solid phase}

Particles trajectories are predicted by integrating the force balance on the particle. In this balance the particle inertia equals the sum of forces exerting on the particle, and can be written (for $\mathrm{x}$ direction) as in [9]:

$$
\frac{d u_{i p}}{d t}=F_{D}\left(u_{i}-u_{i p}\right)+\frac{g_{i}\left(\rho_{p}-\rho\right)}{\rho_{p}}
$$

Where $F_{D}\left(u_{i}-u_{i_{p}}\right)$ represent the drag force per unit particle mass and $\mathrm{F}_{\mathrm{D}}$ is the drag force and calculated from:

$$
F_{D}=\frac{18 \mu}{\rho_{p} d_{p}^{2}} \frac{C_{D} R e}{24}
$$

where $C_{D}$ is the drag coefficient and $u_{p}$ is the particle velocity. $R e$ is the relative Reynolds is:

$$
R e=\frac{\rho d_{p}\left|u_{i_{p}}-u_{i}\right|}{\mu}
$$

The drag coefficient, $C_{D}$ can be taken from

where

$$
C_{D}=\frac{24}{R e_{s p h}}\left(1+b_{1} R e_{s p h}^{b_{2}}\right)+\frac{b_{3} R e_{s p h}}{b_{4}+R e_{s p h}}
$$

$$
\begin{gathered}
b_{1}=\exp \left(2.3288-6.4581 \emptyset+2.4486 \emptyset^{2}\right) \\
b_{2}=0.0964+0.5565 \emptyset \\
b_{3}=\exp \left(4.905-13.8977 \emptyset-18.4222 \emptyset^{2}-10.2599 \emptyset^{3}\right) \\
b_{4}=\exp \left(1.4681+12.2584 \emptyset-20.7322 \emptyset^{2}+15.8855 \emptyset^{3}\right)
\end{gathered}
$$

The shape factor $\emptyset$ is defined as:

$$
\emptyset=\frac{s}{s}
$$

Where $s$ is the surface area of a sphere having the same volume as the particle, and $\mathrm{S}$ is the actual surface area of the particle. The Reynolds number $\operatorname{Re}_{\mathrm{sph}}$ is computed with the diameter of a sphere having the same volume.

\section{Grid Independency and Turbulence Model Selection}

A tetrahedral grid was created by using the meshing tool of available of ANSYS workbench 14.5. The grid independency was investigated to determine the optimal size for the grid using the RNG k- $\varepsilon$ model. This model was recommended for jet flow by Eirik Martin Stuland [12] and Al-Duliami [8]. The grid independency was carried out at the velocity $U_{J}=47 \mathrm{~m} / \mathrm{s}(\operatorname{Re}$ $=31143$ ) for three different grid sizes in order to check the variation of velocity with grid in velocity. Figure 7 shows the air radial velocity distributions for three different cell sizes at $\mathrm{y} / \mathrm{D}=6$. The results show that the distribution is very close and similar. Comparing the average velocity indicates to an increasing from 18.84 to 19.249 (for cell numbers 805070 and 1331067 ) which is about $2.2 \%$. The cell volume of $0.00341 \mathrm{~m}^{3}$ (cells number $=805070$ ) was chosen as the variation in average velocity are very small with higher meshing and the discrepancy between the experimental and predictions of the local values near the centerline are very small. 


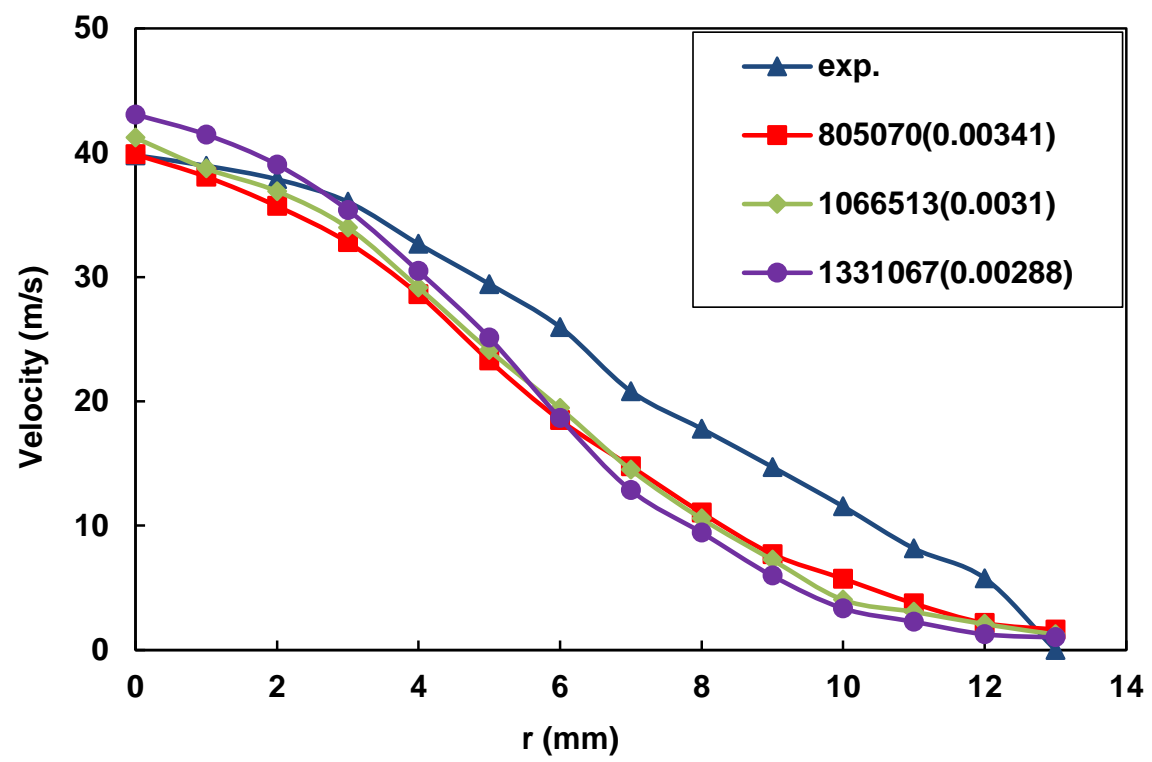

Figure 7. Grid Independence (radial velocity distribution)

\section{RESULTS AND DISCUSSIONS}

\section{Experimental Results}

\section{Single Phase Velocity Measurements}

Figures 8,9 and 10 present the radial velocity profiles at different axial distance to diameter ratio of $(y / D=0,2,4,6$ and 8$)$ and $\left(U_{J}=47,32\right.$ and $\left.15 \mathrm{~m} / \mathrm{s}\right)$ for different distances from the nozzle exit. The figures exhibit a typical behavior of the jet; the maximum velocity is at the jet centerline. A number of distinct regions can be noticed in radial velocity distributions. The jet from the nozzle is characterized by a high velocity with a fairly flat profile reflecting the existence of the potential zone near the nozzle outlet. As moving further axially from the outlet, the jet turns into a free jet zone. This zone is distinguished by a lower velocity and a wider profile. Zuckerman explained the free jet zone in detail [13]. Inside the jet zone the velocity gradients create a shearing layer at the edges of the jet. This layer dissipates momentum outward in lateral direction, pulling additional fluid. In this process, the jet loses energy and the velocity profile becomes wider and decreases in magnitude along the sides of the jet. 


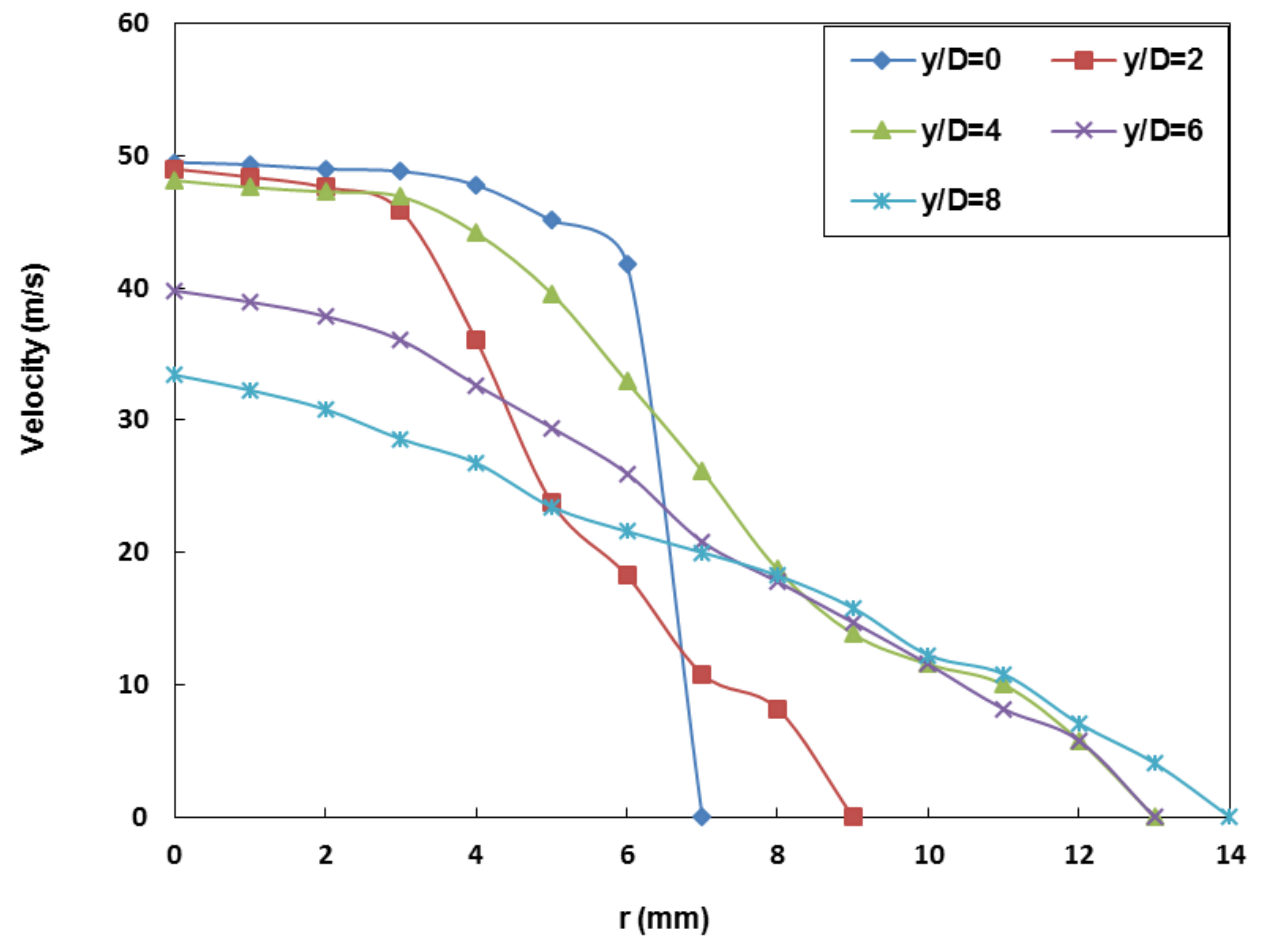

Figure 8. Radial profile of air jet velocity $\left(\mathrm{U}_{\mathrm{J}}=47 \mathrm{~m} / \mathrm{s}\right)$.

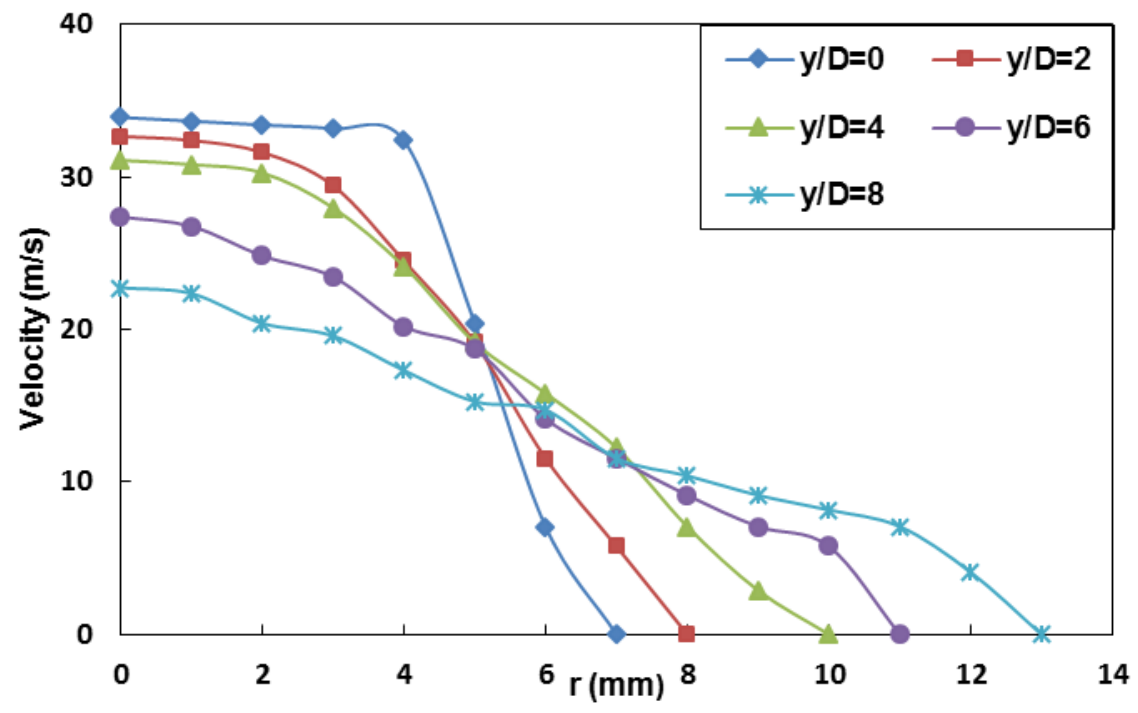

Figure 9. Radial profile of air jet velocity $\left(U_{J}=32 \mathrm{~m} / \mathrm{s}\right)$ 


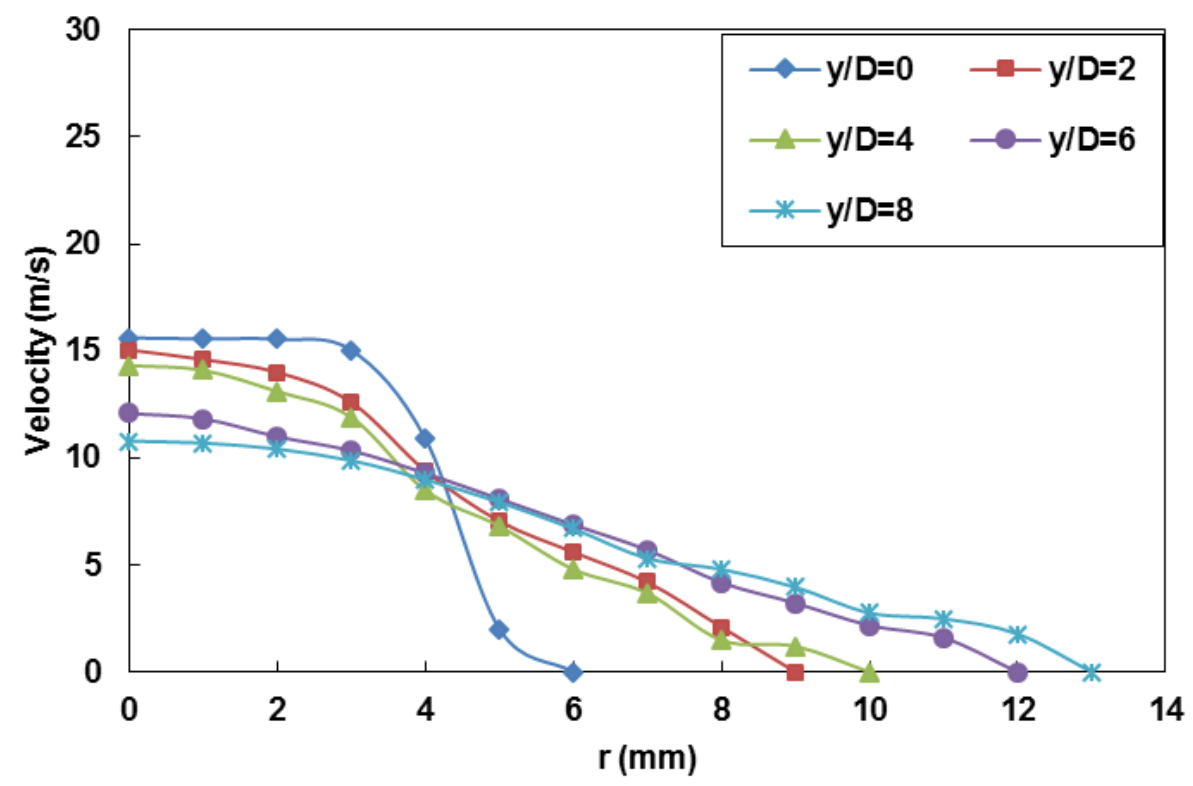

Figure 10. Radial profile of air jet velocity $\left(\mathrm{U}_{\mathrm{J}}=15 \mathrm{~m} / \mathrm{s}\right)$

The velocity variation along the jet axis is shown in Figure 10 for different jet velocities. It shows that the extent of potential core is of length about four times of the nozzle diameter 4D, this is in consistency with results from previous work $[14,15]$. The extent of the potential core is defined as the distance from the nozzle exit plane to the point of intersection of the constant, issuing velocity in the air jet axis and the curve of the hyperbolic decrease of the centerline velocity. It can be noticed that as the jet velocity decreases the extent of potential core region decreases due to reduction in jet kinetic energy. It is noticed that the axial velocity decreases with distance from the nozzle exit due the degradation of kinetic energy with distance from the nozzle exit [16].

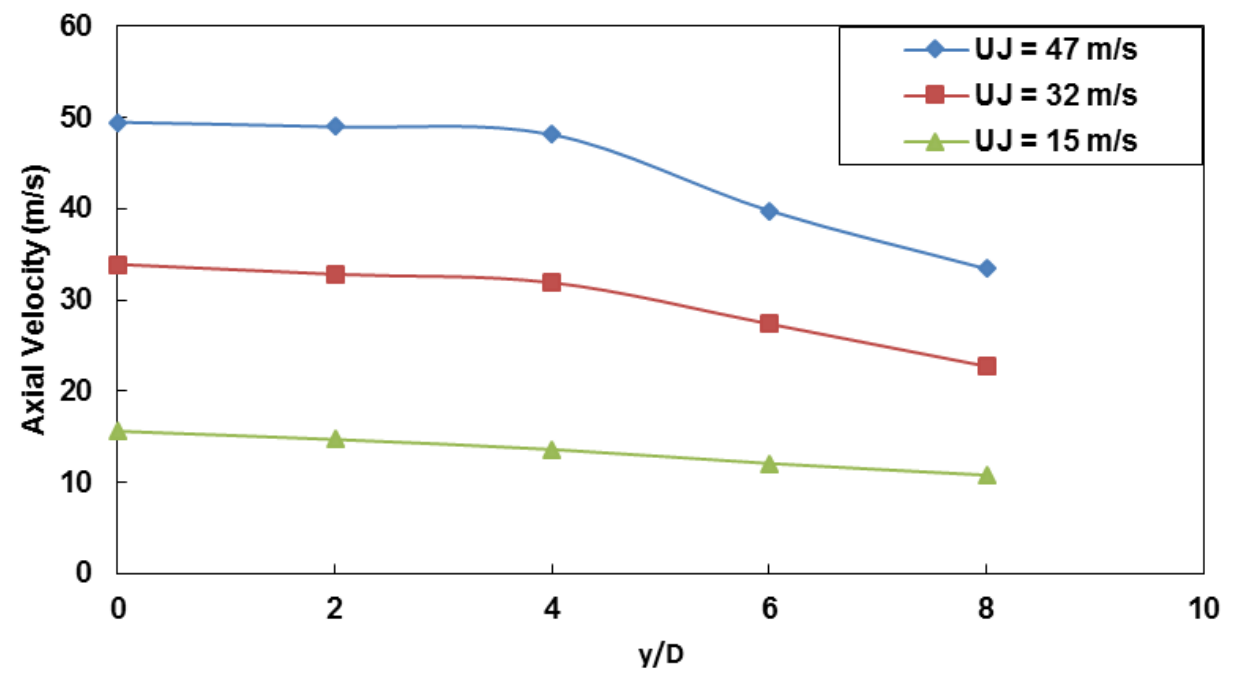

Figure 10. Axial distribution of air jet velocity 


\section{Two Phase Velocity Measurements}

The radial velocity profiles at many axial locations (y/D) are presented in Figures 11, 12, 13, 14 and 15. The sand particles have an immediate effect on the gas phase. It can be observed that as loading ratio increases, the decay of the air velocity increases and the spreading rate decreases this is attributed to the transfer of air momentum to the particles and surrounding air, and so air velocity rapidly decreases [2].

Figure 11 represents the effect of sad particle o air velocity at nozzle exit. The velocities of air at the nozzle exit for both cases of single and two- phase are the same regardless of the particle presence. It can be concluded that the air velocities at the nozzle exit for both air and air-solid jet are nearly the same because of the influence of particle is small due to high inertia of the air. This trend is similar to that observed by Paik [2] and Cushman [17].

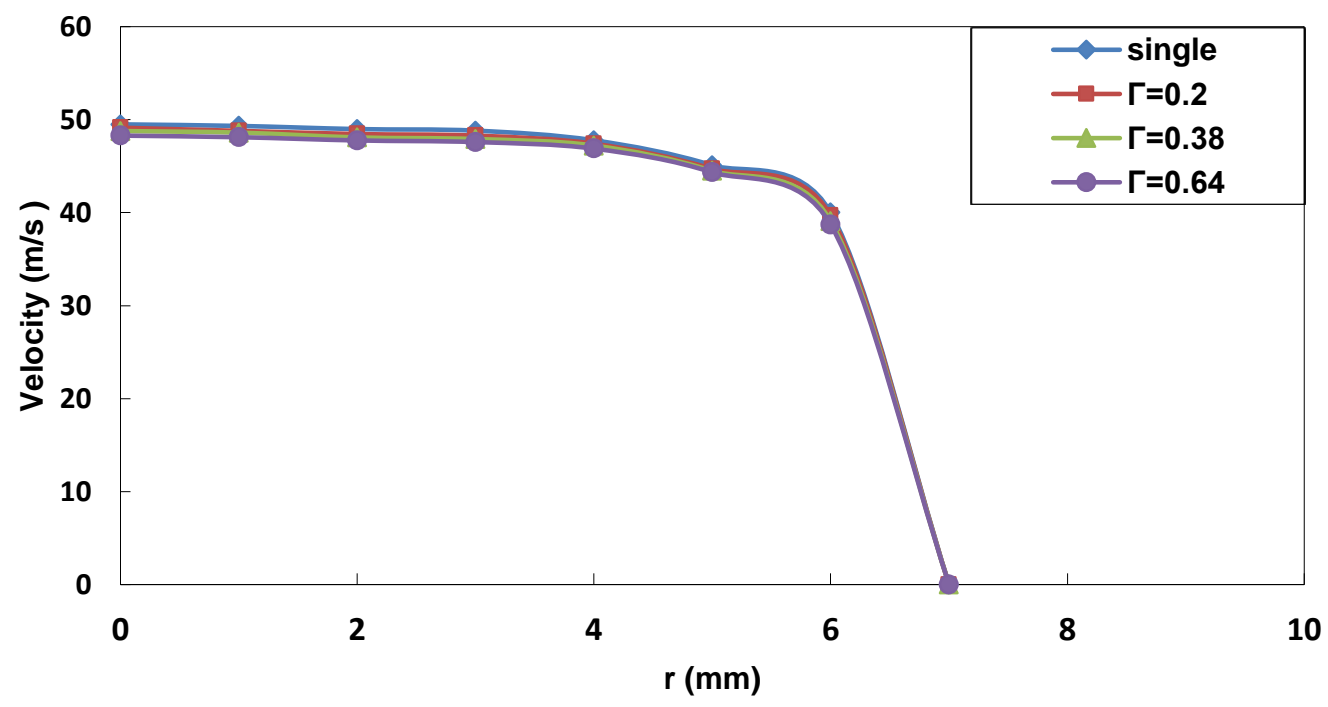

Figure 11. Radial profile of jet velocity at $\mathrm{y} / \mathrm{D}=0\left(\mathrm{U}_{\mathrm{J}}=47 \mathrm{~m} / \mathrm{s}, \mathrm{dp}=550 \mu \mathrm{m}\right)$

As the axial distance to diameter ratio (y/D) increases the effect of particle becomes stronger on the air velocity as in Figures 12,13,14 and 15. This is because the particles keep accelerating by receiving the momentum from the air leading to suppress the air velocity (Paik [2]). The sand particles influence on the air velocity decreases as the radius increases because the particle concentration decreases with radial distance (Fleckhaus [1]). 


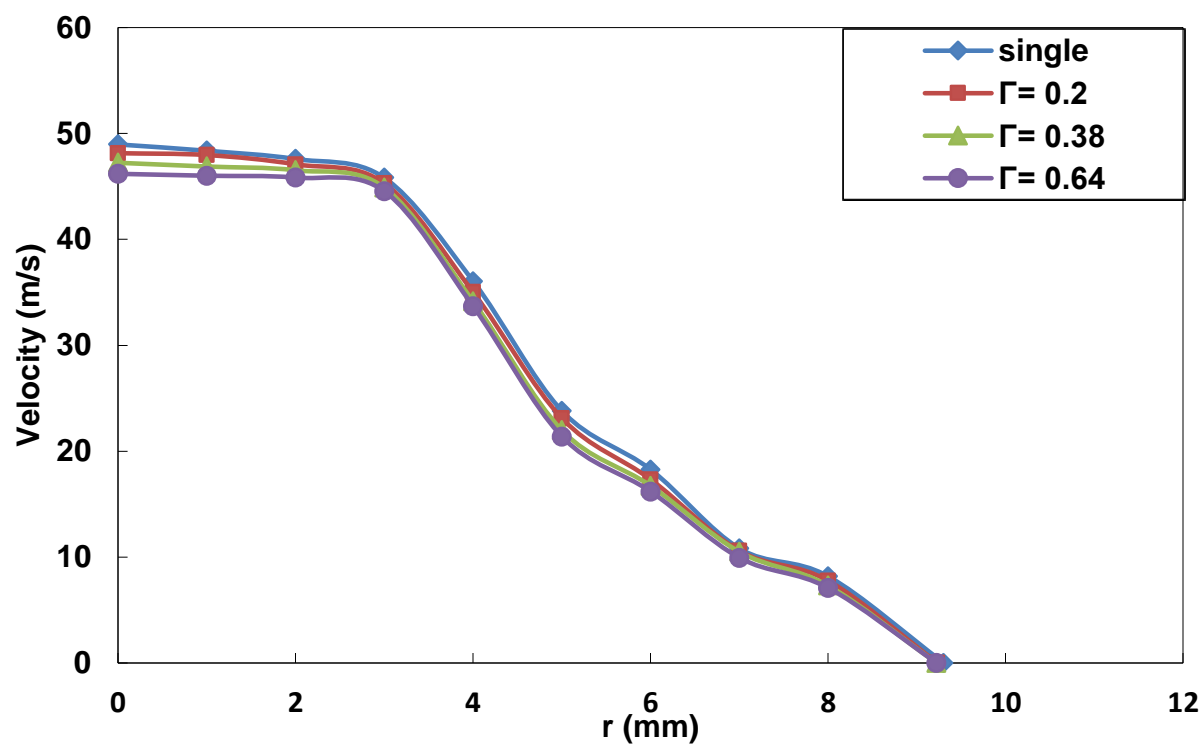

Figure 12. Radial profile of air jet velocity at $y / D=2\left(U_{J}=47 \mathrm{~m} / \mathrm{s}, \mathrm{d}_{\mathrm{p}}=550 \mu \mathrm{m}\right)$.

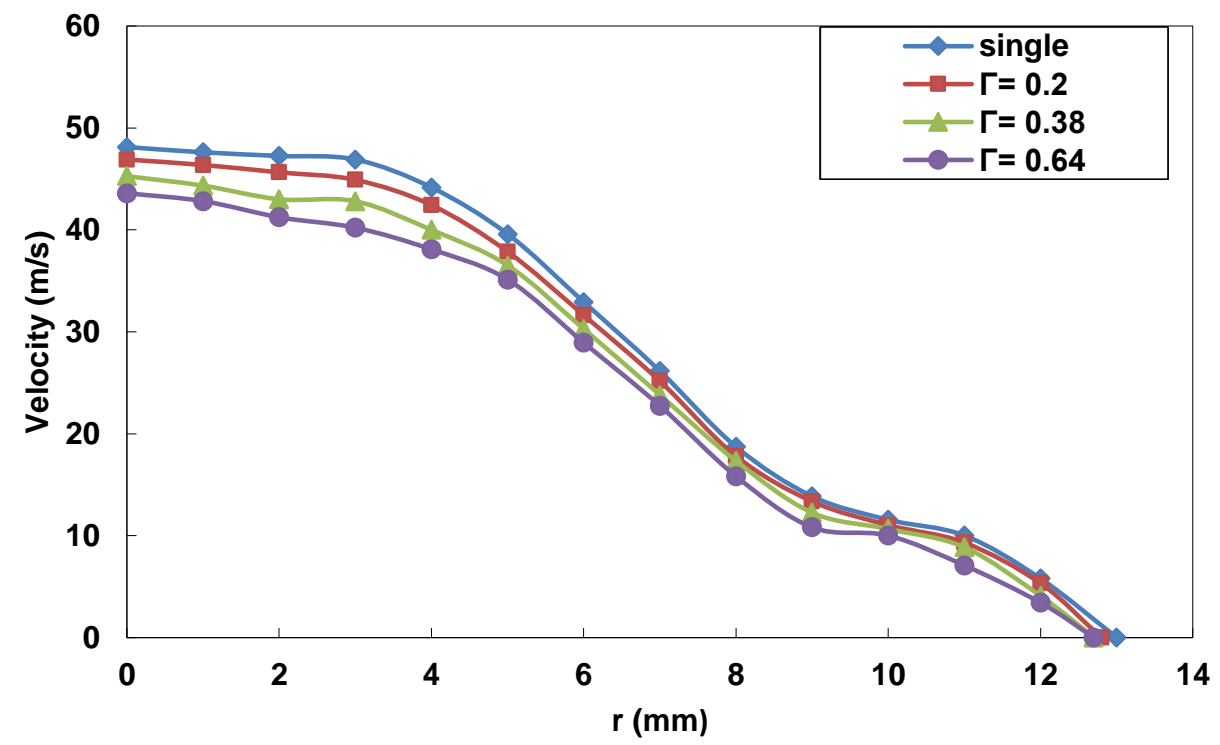

Figure 13. Radial profile of air jet velocity at $y / D=4\left(U_{J}=47 \mathrm{~m} / \mathrm{s}, d_{p}=550 \mu \mathrm{m}\right)$. 


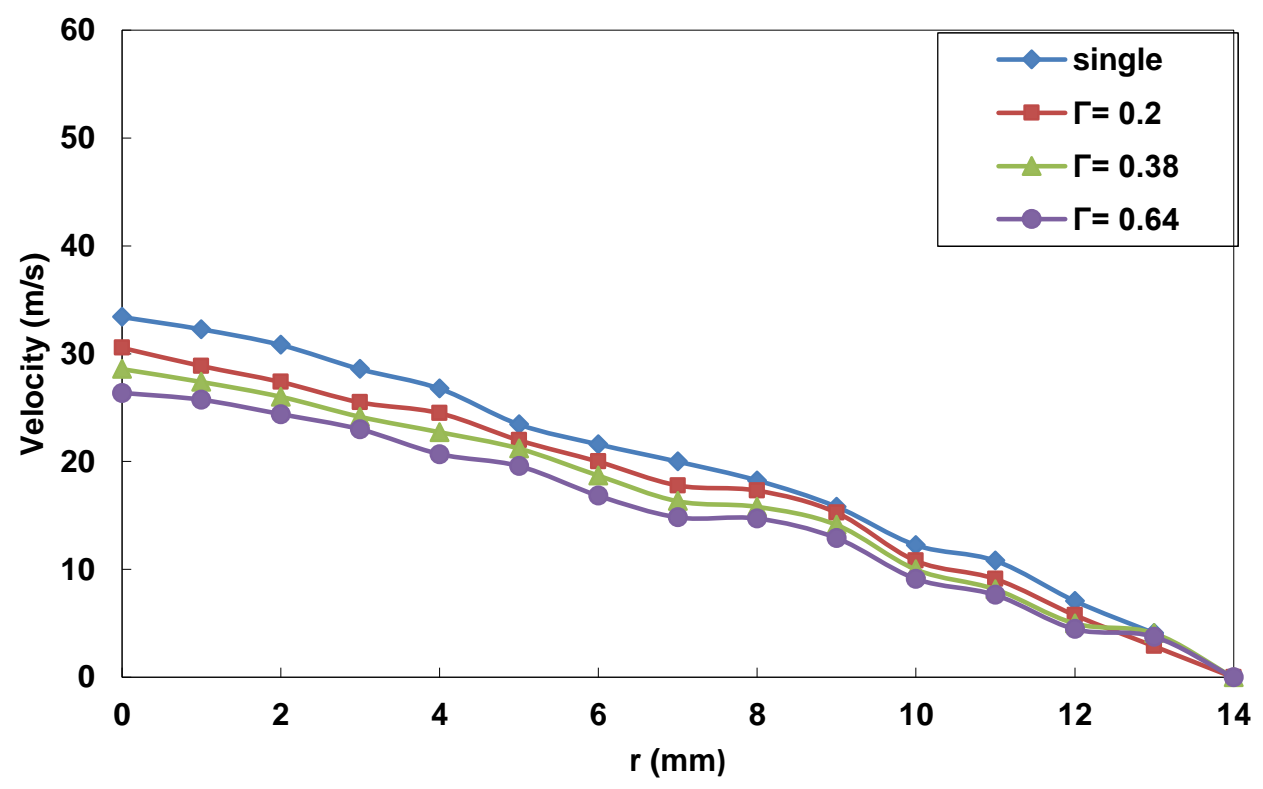

Figure 14. Radial profile of jet velocity at $y / D=6\left(U_{J}=47 \mathrm{~m} / \mathrm{s}, \mathrm{d}_{\mathrm{p}}=550 \mu \mathrm{m}\right)$.

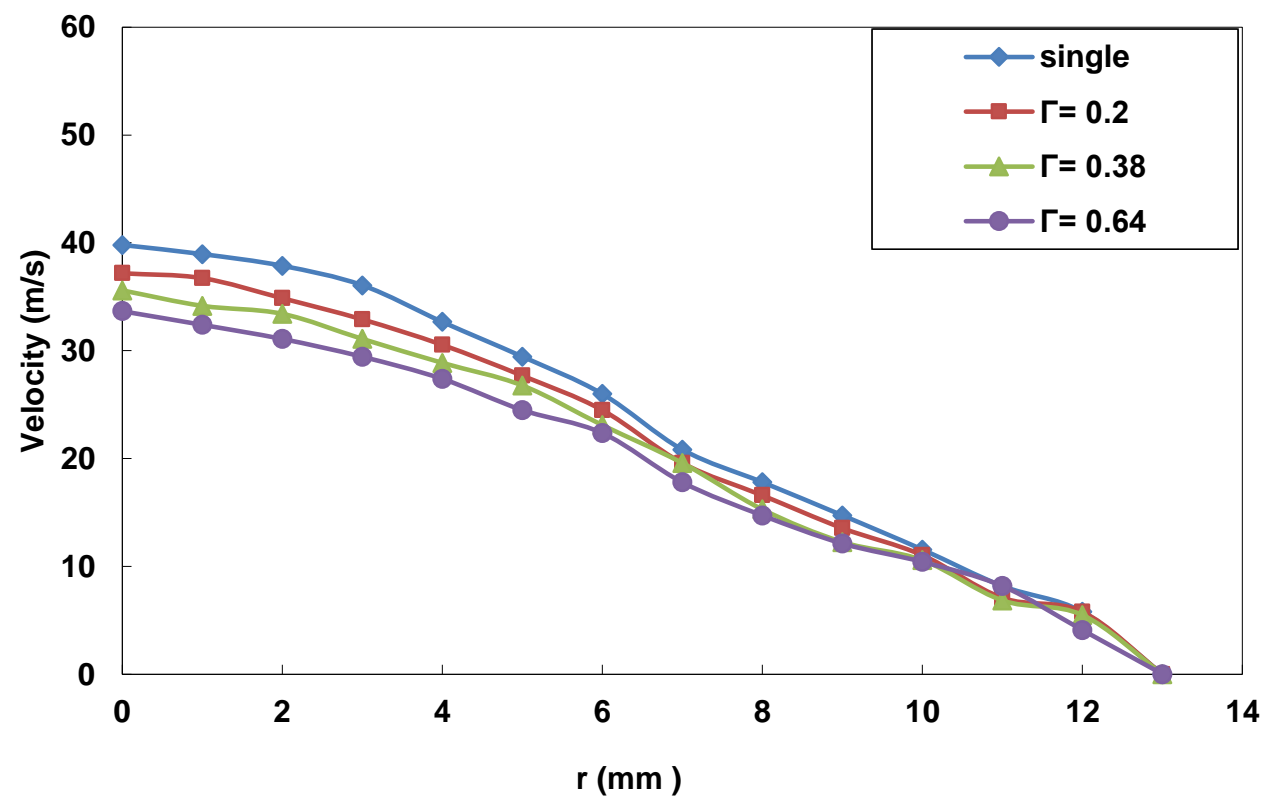

Figure 15. Radial profile of jet velocity at $\mathrm{y} / \mathrm{D}=8\left(\mathrm{U}_{\mathrm{J}}=47 \mathrm{~m} / \mathrm{s}, \mathrm{d}_{\mathrm{p}}=550 \mu \mathrm{m}\right)$. 
Figure 16 presents the axial velocity for different loading ratios for $U_{J}=47 \mathrm{~m} / \mathrm{s}$ and $\mathrm{d}_{\mathrm{p}}=550 \mu \mathrm{m}$. When the jet exits, the air momentum is transferred to the particles and surrounding, due to that transfer the air velocity decreases rapidly. Meanwhile, the transferred momentum to the particles leads to accelerate them. It's observed that as loading ratio increases the reduction in velocity increased, this conclusion agrees with Paik [2]. This is because the larger number of particles in the flow the larger momentum received from air causing reduction in velocity. Also, it can be noticed that the core region extension decreases with the presence of natural sand particles, this is because the damping effect.

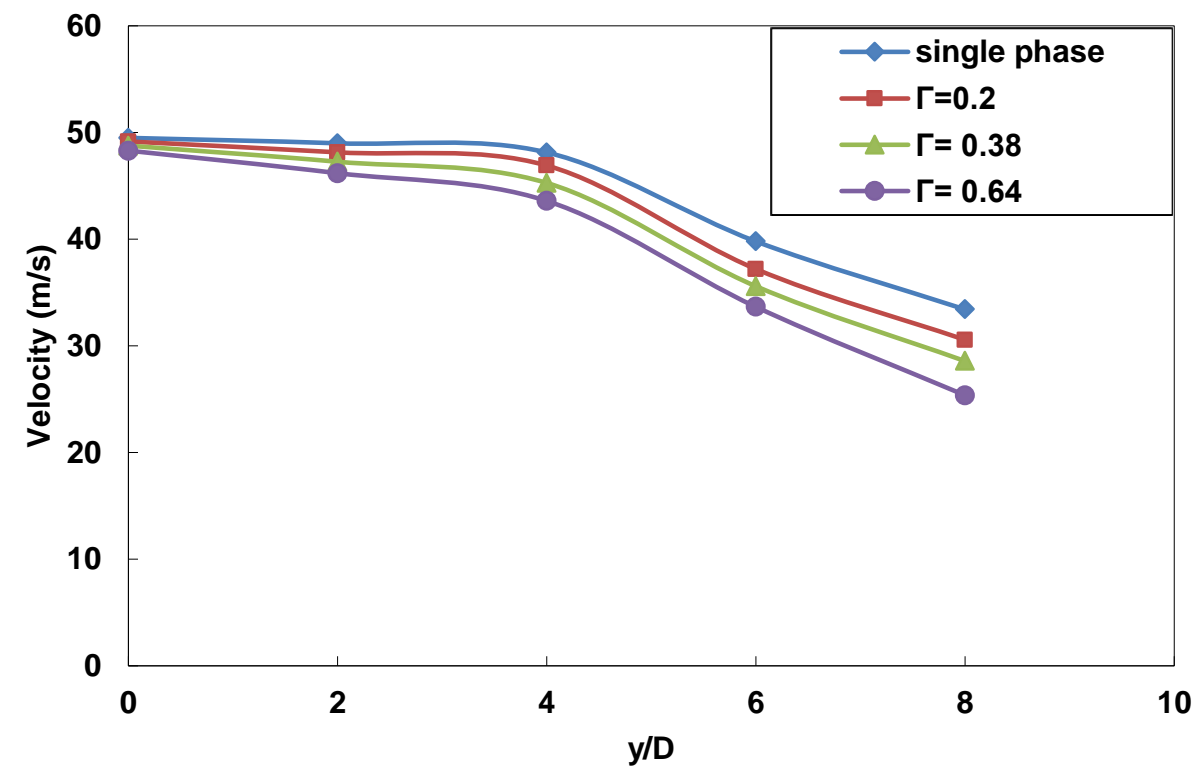

Figure 16. Axial profile of jet velocity for different loading ratios $\left(U_{J}=47 \mathrm{~m} / \mathrm{s}, \mathrm{d}_{\mathrm{p}}=\right.$ $550 \mu \mathrm{m})$.

The variation of radial velocity profile with particle size is shown in Figure 17. It's obvious that velocity depression increases for particles of smaller size. This because the effect of dampening increases due to larger number of particles which interface with a greater number of eddies in the air phase which is consistent with Fleckhaus [1]. The same behaviour is observed for the axial profile of jet velocity with smaller particles as shown in Figure 18. 


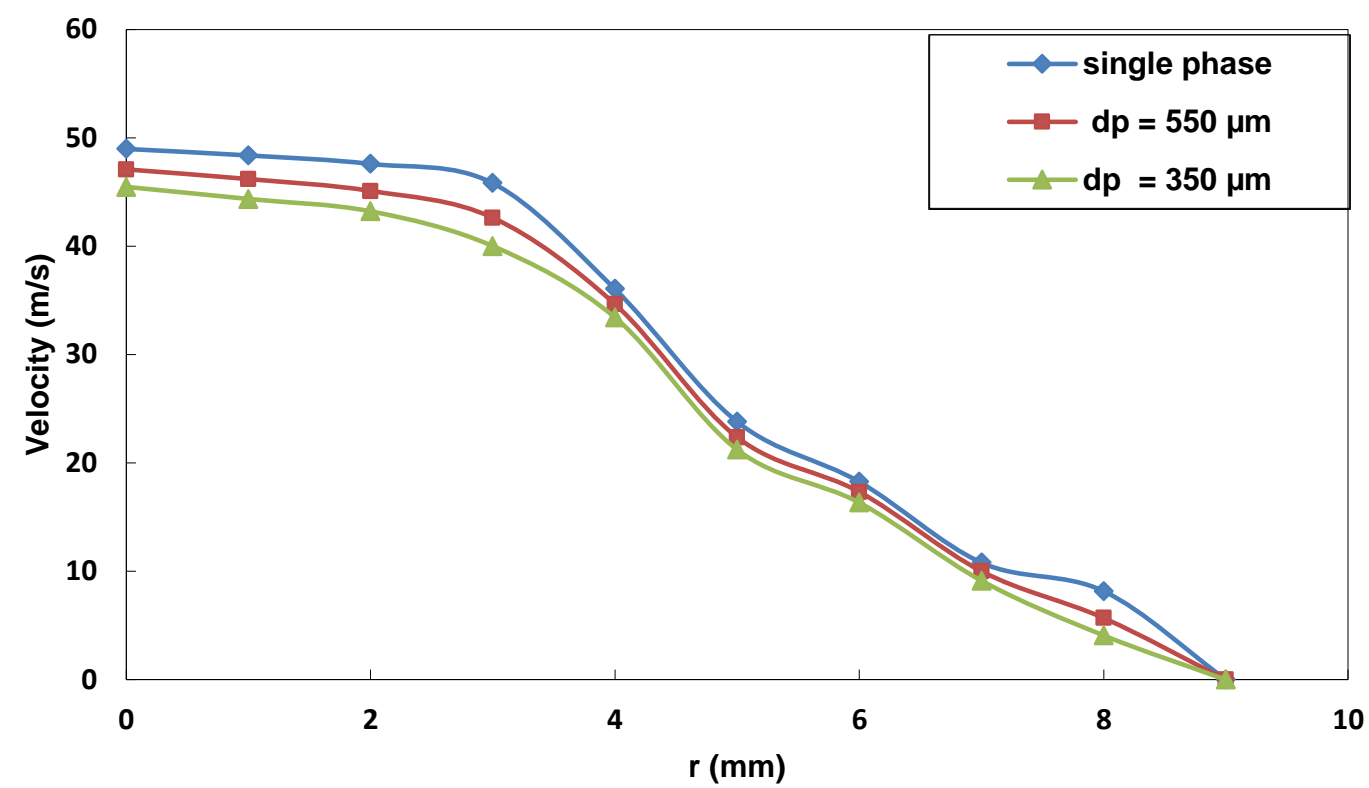

Figure 17. Radial profile of jet velocity for two particle diameters $\left(U_{\mathrm{J}}=47 \mathrm{~m} / \mathrm{s}, \mathrm{y} / \mathrm{D}=2\right.$, $\Gamma=0.7)$.

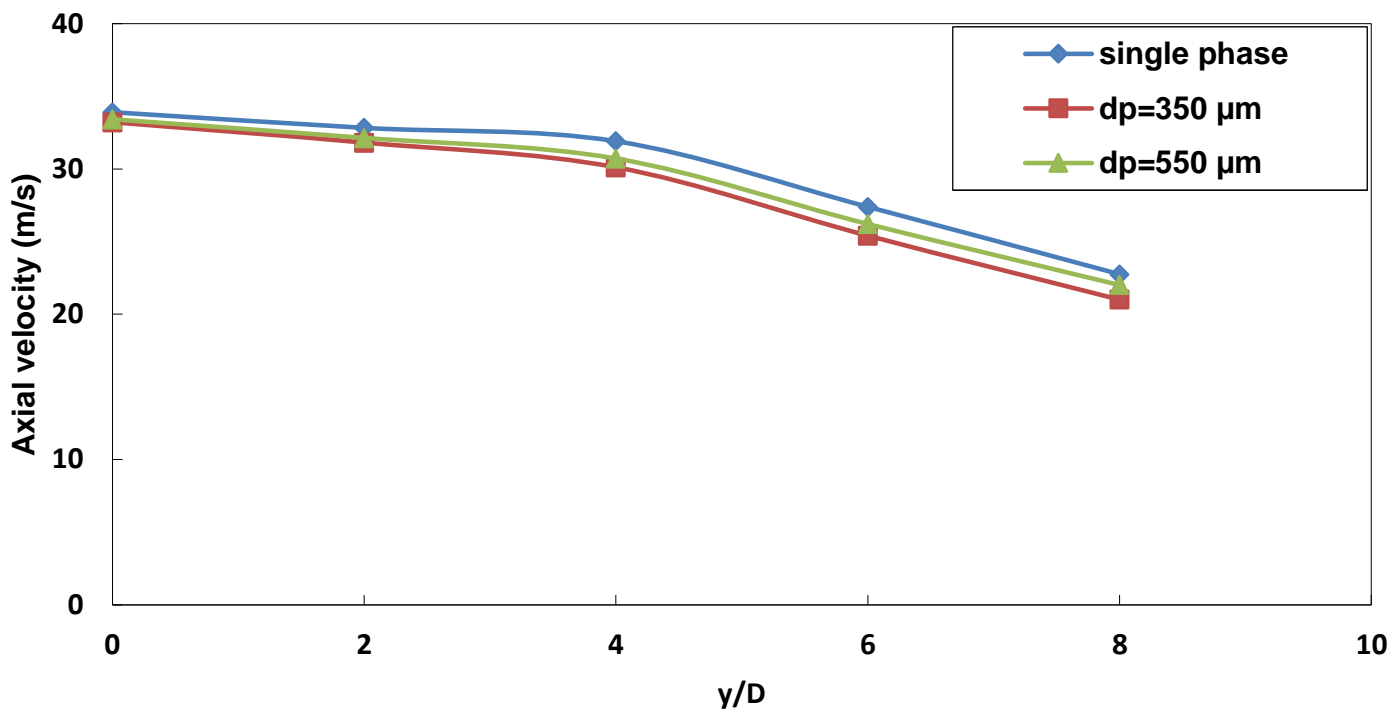

Figure 18. Axial profile of jet velocity for two particle diameters $\left(\mathrm{U}_{\mathrm{J}}=32 \mathrm{~m} / \mathrm{s}\right.$, $\Gamma=0.7)$. 


\section{Numerical Results}

\section{Single Phase Results}

Figures 19 and 20 represent a comparison between experimental and numerical radial profiles of velocities $U_{J}=47$ and $32 \mathrm{~m} / \mathrm{s}$ at different axial locations. They reveal a good agreement between experimental and numerical radial velocity profiles. The maximum average discrepancy between experimental and numerical is $6 \%$ which is acceptable.

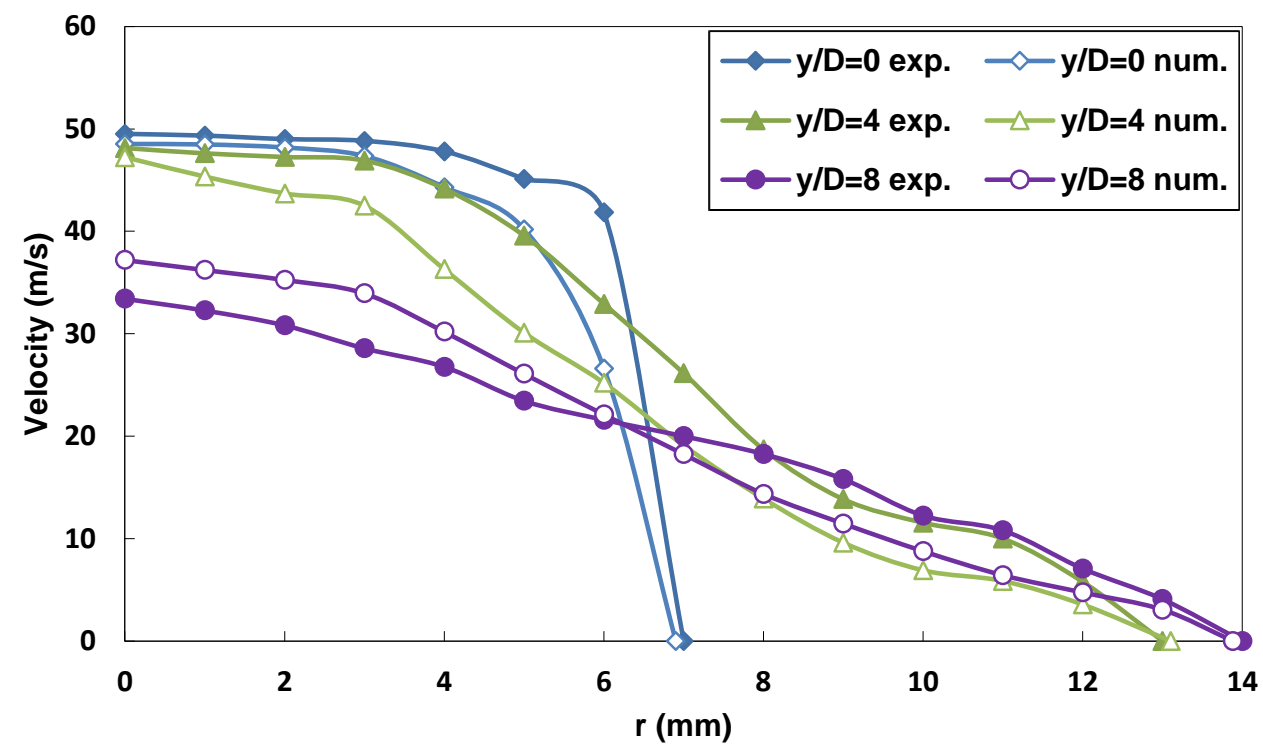

Figure 19. Radial profile of jet velocity at different $\left(\mathrm{U}_{\mathrm{J}}=47 \mathrm{~m} / \mathrm{s}\right)$

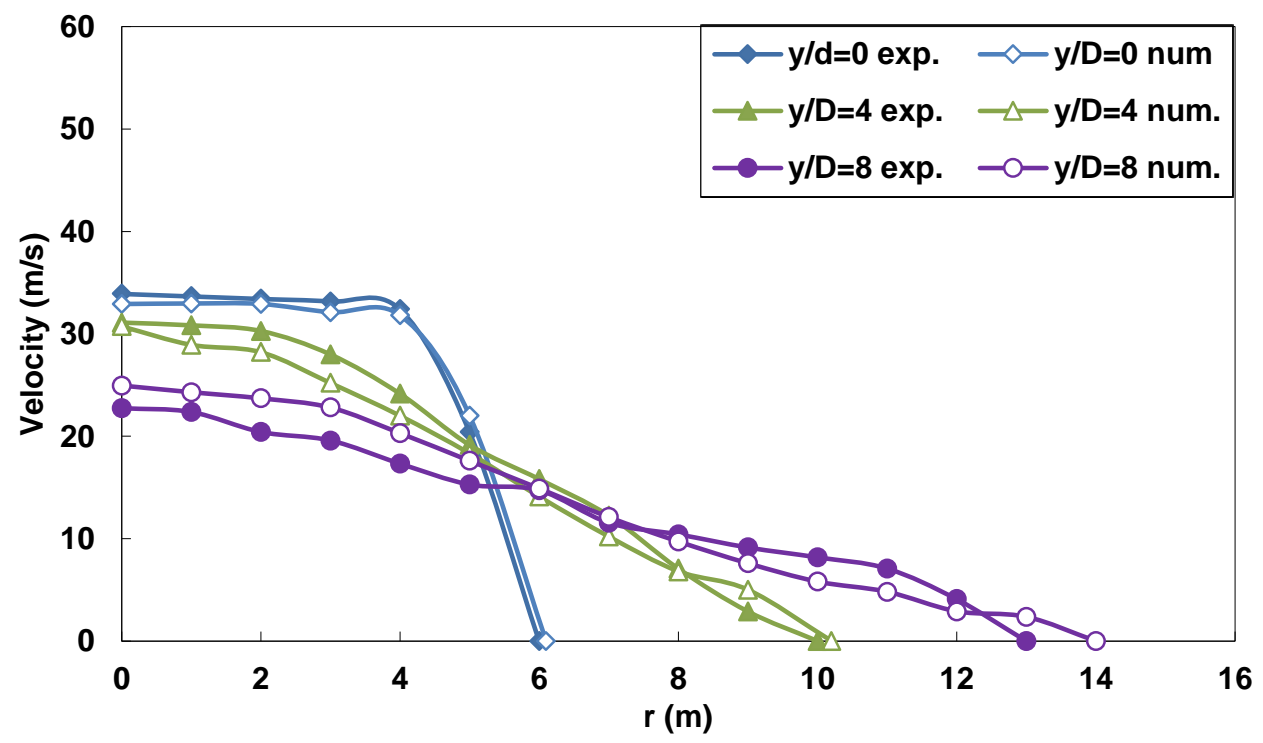

Figure 20. Experimental and numerical radial profile of jet velocity $\left(\mathrm{U}_{\mathrm{J}}=32 \mathrm{~m} / \mathrm{s}\right)$. 
A comparison between experimental and numerical of axial profile of jet velocity for different velocities is shown in Figure 21. It reveals a good agreement and supports the result of core region ends at $\mathrm{y} / \mathrm{D}=4$. The maximum average discrepancy between experimental and numerical results is $\mp 4 \%$.

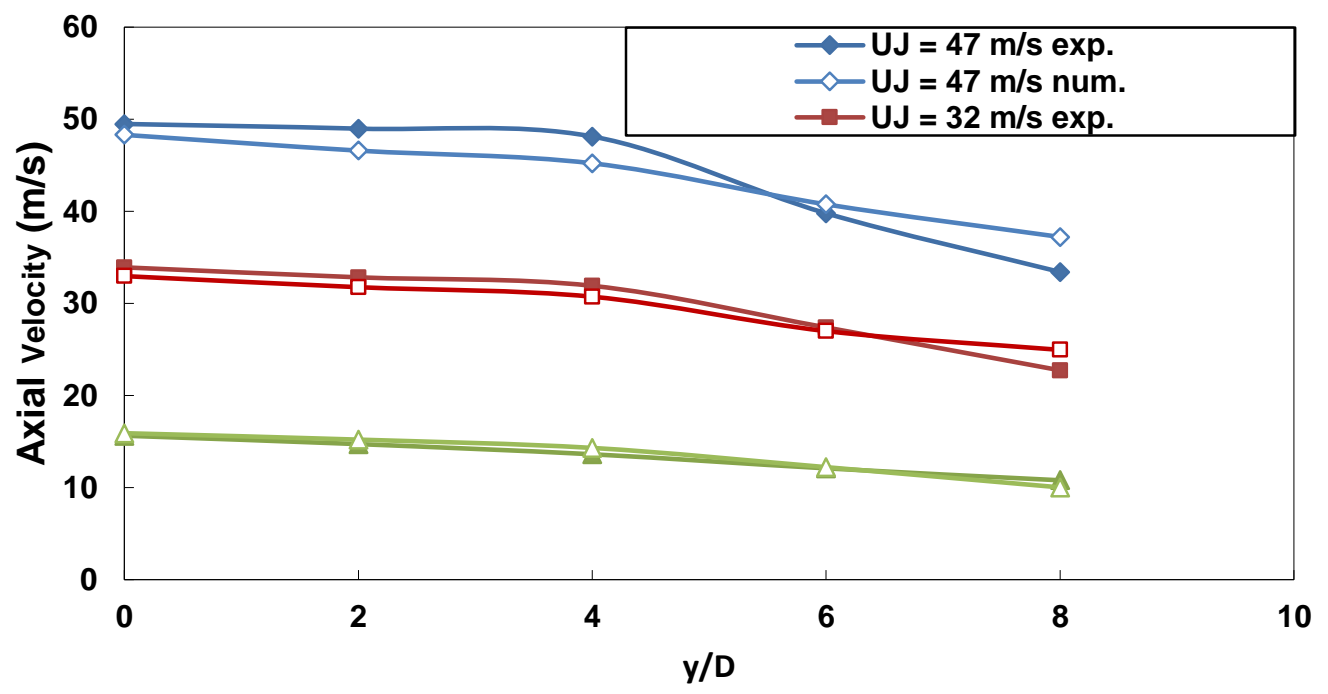

Figure 21. Experimental and numerical axial profile of jet velocity

\section{Two Phase Results}

Figures 22 and 23 represent a comparison between experimental and numerical radial profile of jet velocity for single and two- phase flow of $U_{\mathrm{J}}=47 \mathrm{~m} / \mathrm{s}$ and $\mathrm{y} / \mathrm{D}=0,4,8$. It can be noticed that there is a good consistency between experimental and numerical result for single and two- phase flow. It is observed that at the nozzle exit effect of particles this effect decreases radially.

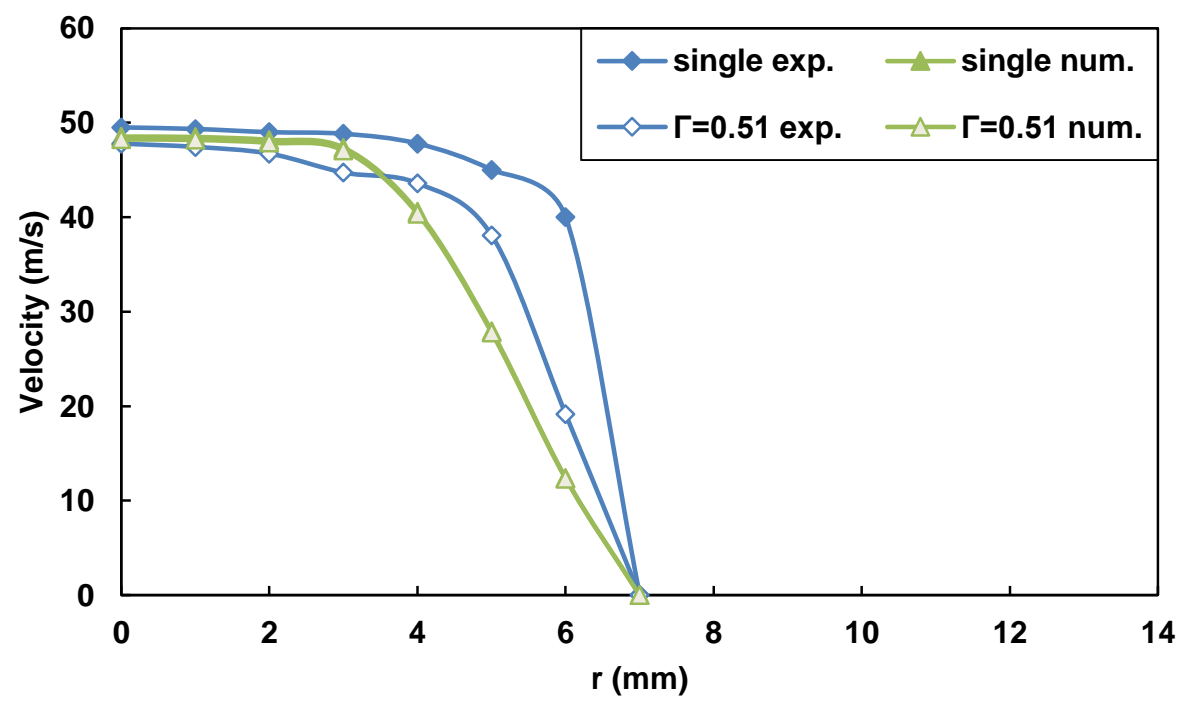

Figure 22. Experimental and numerical radial profile of jet velocity for single and twophase flow $\left(\mathrm{UJ}_{\mathrm{J}}=47 \mathrm{~m} / \mathrm{s}, \mathrm{y} / \mathrm{D}=0\right)$ 


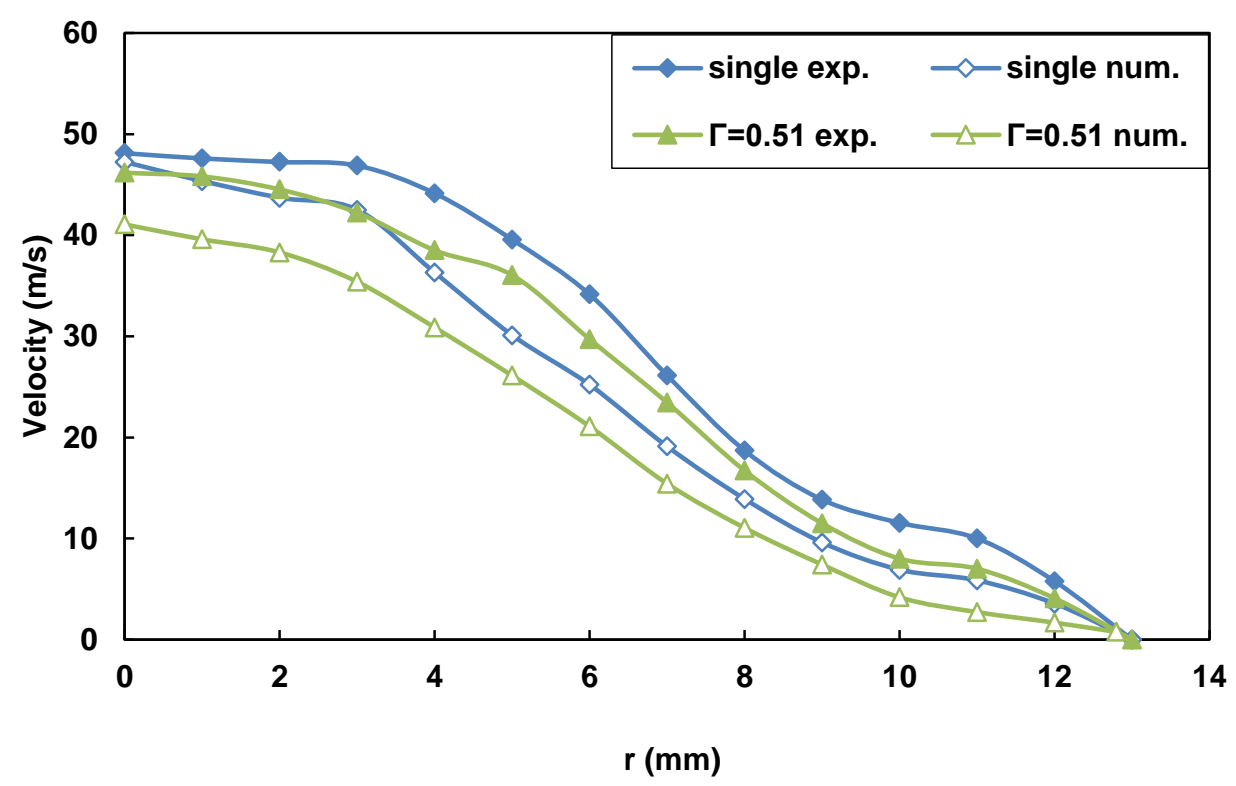

Figure 23. Experimental and numerical radial profile of jet velocity for single and two phase flow $\left(\mathrm{UJ}_{\mathrm{J}}=47 \mathrm{~m} / \mathrm{s}, \mathrm{y} / \mathrm{D}=4\right)$

\section{CONCLUSIONS}

The effect of introducing natural sand particles on the structure of air jet flow was investigated. Loading ratio and particles size effects on the structure of the jet velocity was investigated experimentally and numerically. Ansys-Fluent was used to simulate the flow structure. The following points can be concluded from the present work:

1. The attenuation of air velocity by particles decreases radially because particle concentration decreases radially.

2. Sand particles dampens the turbulence of the flow.

3. The flow at nozzle exit doesn't strongly influenced ay particles due to the high inertia in this region.

4. Size of particles has a significant impact on the flow. The smaller particle size the higher number of particles per unit volume leading to higher velocity reduction.

5. The potential core region is strongly affected by solid particles 


\section{REFERENCES}

[1] Fleckhaus D, Hishida K, Maeda M. Effect of laden solid particles on the turbulent flow structure of a round free jet. Experiments in Fluids, 1987; 5 (5):323-333.

[2] Paik KY, Yoon JS, Hwang JJ, Chung JM, Bouvet N, Yoon YB. Effect of particle loading ratio and orifice exit velocity on a particle-laden jet. International Journal of Aeronautical and Space Sciences, 2011; 12(3): 296-304.

[3] Tsuji, Morikawa Y, Tanaka T, Karimine K, Nishida N. Measurement of an axisymmetric jet laden with coarse particles. International Journal of Multiphase Flow, 1988; 14(5): 564-574.

[4] Stakić MB, Živković GS, Sijerčić MA. Numerical analysis of discrete phase induced effects on a gas flow in a turbulent two-phase free jet. International Journal of Heat and Mass Transfer, 2011; 54(12):2262-2269.

[5] Zoltani CK, Bicen AF. Velocity measurements in a turbulent, dilute, two-phase jet. Experiments in Fluids, 1990; 9(5):295-298.

[6] Gui N, Fan J, Chen S. Numerical study of particle-vortex interaction and turbulence modulation in swirling jets. Physical Review 2011;82 (5); 1-10.

[7] Pandaba P, Ashok KB, Brundaban P. Computational Study of a turbulent gas-solid confined jet flow. Powder Technology, 2016; 297: 229-238.

[8] Mustafa JD, Adnan AAR, Faik A. Hamad. Investigation of impingement heat transfer for air-sand mixture flow. Canadian Journal of Chemical engineering, 2016;94 (1): 134-141.

[9] ANSYS FLUENT Theory Guide, Release 14.5, November 2012.

[10] Pulat E, Isman MK, Etemoglu AB. Effect of Turbulence Models and Near-Wall Modelling Approaches on numerical results in impingement heat transfer. Numerical Heat Transfer, Part B: Fundamentals, 2011; 60(6):486-519.

[11] Heck U, Fritsching U, Bauckhage K. Fluid flow and heat transfer in gas jet quenching of a cylinder. International Journal of Numerical Methods for Heat \& Fluid Flow, 2011; 11(1): 36-49.

[12] Eirik MS. Computation of impinging gas jet. Master of Science in Product Design and Manufacturing, Norwegian university of science and technology; 2008.

[13] Zuckerman N, Lior N. Jet impingement heat transfer: physics, correlations, and numerical modelling. Advances in Heat Transfer, 2006; 565-631.

[14] Warda H, Kassab S, Elshorbagy K, Elsaadawy E. An experimental investigation of the near-field region of a free turbulent coaxial jet using LDA. Flow Measurement and Instrumentation, 1999; 10(1): 15-26.

[15] Warda H, Kassab S, Elshorbagy K, Elsaadawy E. Influence of the magnitude of the two initial velocities on the flow field of a coaxial turbulent jet. Flow Measurement and Instrumentation, 2011; 12(1): 29-35.

[16] Bergman TL, Lavine AS, Frank PI, David PD. Fundamentals of heat and mass transfer. $8^{\text {th }}$ ed. New York: John Wiley and Sons; 2017.

[17] Cushman. Environmental fluid mechanics. New Hampshire: John Wiley and Sons; 2008. 